\title{
O RESGATE DE PAULO FREIRE PARA O PROJETO-LIBERTAÇÃO DE ENRIQUE DUSSEL
}

\section{JOÃO PAULO PIMENTEL ${ }^{1}$ E EDUARDO FERREIRA CHAGAS ${ }^{2}$}

\begin{abstract}
RESUMO: O presente artigo objetiva expor a apropriação do filósofo Enrique Dussel das ideias pedagógicas de Paulo Freire. Apresentaremos o itinerário da Ética da Libertação referente ao nível moral-formal crítico na superação da Ética do Discurso em vista do projetolibertação. Neste sentido, o pensamento de Paulo Freire possibilita o avanço para um critério de validade consensual anti-hegemônico mediante a formação das comunidades de vítimas. Dussel, acolhe, portanto, o processo de conscientização e a ação dialógica propostos por Freire como elementos fundamentais da Ética da Libertação.
\end{abstract}

PALAVRAS-CHAVE: Enrique Dussel. Paulo Freire. Práxis.

ABSTRACT: This paper aims to expose the philosopher Enrique Dussel's appropriation of Paulo Freire's pedagogical ideas. We will present the itinerary of the Ethics of Liberation regarding the moral-critical level in overcoming the Discourse Ethics in perspective of the liberation project. Thereby, Paulo Freire's thought makes it possible to advance to an antihegemonic validity criterion through the formation of communities of victims. Dussel therefore accept the process of critical consciousness and dialogical action proposed by Freire as fundamental elements of the Ethics of Liberation.

KEYWORDS: Enrique Dussel. Paulo Freire. Praxis

Inspirado por uma necessidade real do seu tempo histórico - os movimentos de libertação em contraste aos regimes militares que perduraram na América Latina a partir da metade do século passado - Enrique Dussel elaborou um pensar autêntico e próprio dos povos oprimidos, uma filosofia original que não se limita ao âmbito puramente teórico, mas que alcança, graças ao método analético ${ }^{3}$, uma práxis de libertação.

Tendo iniciado sua atividade filosófica no final dos anos 60, Dussel pôde manter um diálogo crítico com autores contemporâneos e atualizar seu próprio pensamento conforme

\footnotetext{
${ }^{1}$ Doutorando em Educação pela Pós-Graduação em Educação da Universidade Federal do Ceará (UFC), Mestre em Ética e Filosofia Política (UFC) e Professor da Rede Pública de Fortaleza-Ce. E-mail: pimentelpaulolima@gmail.com.

${ }^{2}$ Professor Associado IV da Graduação e Pós-Graduação do Curso de Filosofia da Universidade Federal do Ceará (UFC) e Colaborador do Programa de Pós-Graduação em Educação Brasileira da Faculdade de Educação da Universidade Federal do Ceará (FACED-UFC). Pq - Pesquisador e Bolsista do CNPq. Doutor em Filosofia pela Universidade de Kassel (Alemanha).E-mail: ef.chagas@uol.com.br.

${ }^{3} \mathrm{O}$ método analético configura-se como um momento crítico do método dialético. Não se limita à teoria, mas lança-se à práxis. Parte da interpelação do outro ao questionar a totalidade e desenvolve-se de forma concreta, prática (DUSSEL, 1977, p. 164).
} 
subsumia novas perspectivas teóricas, ao mesmo tempo em que novos eventos mundiais irrompiam no decorrer da história. Assim, sua filosofia que nasce em debate com, por exemplo, Martin Heidegger e Paul Ricoeur, vai, aos poucos, ganhando contornos menos fenomenológicos e hermenêuticos para redescobrir Karl Marx. A Filosofia da Libertação deve muito ao trabalho de Marx, mas não se constitui apenas como um comentário marxista. Vai mais além. Dialogando criticamente com filósofos contemporâneos (Emmanuel Lévinas, Ernst Bloch, Paulo Freire e, principalmente, Karl-Otto Apel), ela não deixa de colher os frutos da tradição filosófica ou dos éticos do seu tempo (por exemplo, Alasdair McIntyre, Charles Taylor, Jurgen Habermas e Franz Hinkelammert). Dussel não realiza um trabalho original desconsiderando o que já foi realizado, pelo contrário, com extremo rigor ele destaca os pontos positivos e as limitações de cada ética moderna ${ }^{4}$ para afirmar que, em nenhum momento, filósofo algum incluiu no seu horizonte teórico o povo oprimido latino-americano ou pensou sua libertação. Assim se constitui a tarefa dessa filosofia como ciência social crítica ${ }^{5}$ : pensar a partir das vítimas e com as vítimas as causas de sua opressão objetivando estratégias para uma práxis factível de libertação (DUSSEL, 2012, p. 563).

Apesar de entender a Ética como filosofia primeira ${ }^{6}$, todo o pensamento filosófico de Dussel dialoga com outras áreas (a erótica, a pedagógica e a política) de modo que não seria possível construir uma arquitetura teórica que culminasse na práxis de libertação sem passar por diversos momentos, e entre eles há um nível pedagógico libertador. O objetivo da Ética, a práxis de libertação, é, na verdade, o último de uma série de momentos do projeto-libertação. Sem a tomada de consciência das vitimas de sua própria condição de exclusão nenhum projeto de libertação se tornaria factível. A construção de uma comunidade de comunicação crítica, a concretização da práxis por meio das frentes de libertação (partidos políticos, movimentos sociais, organismos da sociedade civil autônomos etc.) ou as ações de uma política libertadora, não seriam possíveis sem o momento fundamental da conscientização. Destacaremos, portanto, a apropriação que Dussel realiza do pensamento de Freire, especialmente na Ética da Libertação. Nossa abordagem consistirá na exposição da filosofia ética de Enrique Dussel, do

\footnotetext{
${ }^{4}$ Estudo realizado na obra Ética da Libertação (DUSSEL, 2012).

${ }^{5}$ Discorrendo sobre as tarefas e os problemas próprios da Filosofia da Libertação, argumenta Oliveira: "Justamente porque nossos países têm dívida externa, que não podem pagar, porque milhões de nossas crianças morrem antes de completar o primeiro ano de vida, porque a maioria de nosso povo vive em extrema pobreza, a filosofia tem de ter a coragem de refletir a partir da situação concreta e se confrontar com esses problemas. Através disso, a filosofia se transforma: ela é sempre reflexão situada (seu lado genético); na América Latina, ela deve ser uma reflexão a partir da pobreza, isto é, ela tem a tarefa de se articular enquanto filosofia da libertação" (2010, p. 208).

${ }^{6}$ Com o tempo, Dussel passa a referir-se a sua filosofia como uma Ética, sendo a ética entendida como filosofia primeira (2012, p. 543).
} 
caminho da conscientização à formação das comunidades críticas, em diálogo com a Pedagogia do Oprimido.

\section{Educação, Teoria e Práxis.}

Desde suas primeiras obras, Dussel já posiciona a educação (ou a pedagógica) num lugar de prestígio de sua filosofia ${ }^{7}$. De fato, o filósofo argentino sempre recorreu a um profundo rigor teórico, mesmo nos seus primeiros escritos, e, apesar de ter sempre a ética como pano de fundo, nunca deixou de relacionar os vários campos que circundam a vida humana. A erótica, a pedagógica, a cultura popular, a ética e a política estão todas interligadas no quadro teórico da Filosofia da Libertação. Educação e libertação, sem dúvidas, caminham lado a lado numa articulação teoria-práxis.

O caráter prático da Filosofia da Libertação é próprio do seu método analético ${ }^{8}$. Para Dussel, a relação "teoria-prática" deve ser orientada ao esforço teórico para uma práxis ética de libertação, que visa à articulação dos grupos vitimados, isto é, dos movimentos sociais, políticos, raciais, de género, ecológicos, étnicos etc., que formam as "frentes de libertação", fundamentadas e legitimadas pela Ética da Libertação (2012, p. 13). Dentro dessa práxis a educação ocupa um lugar proeminente, pensada por Dussel como pedagógica. A pedagogia não se confunde com a pedagógica. Enquanto a primeira se refere à ciência do ensinamento ou aprendizagem, a segunda remete a um panorama maior. Todas as relações de disciplina (mestrediscípulo, pai-filho, político-cidadão etc.) se agrupam na esfera do contato interpessoal, do facea-face; para esse campo, Dussel usa o termo pedagógica (1982, p. 153). Todo saber acumulado é transmitido não só pelas instituições educacionais, mas por diversos outros agentes, como a família e os meios de comunicação. A educação ou a transmissão da cultura não é privilégio

\footnotetext{
${ }^{7} \mathrm{O}$ tema da educação ou da pedagógica encontra-se já nas obras inaugurais da Filosofia da Libertação, como: Para uma Ética da Libertação Latino-Americana (DUSSEL, 1982) e Filosofia da Libertação (DUSSEL, 1977).

${ }^{8} \mathrm{O}$ método analético de Dussel retoma muito da dialética de Marx. Entendendo que a função da dialética é a compreensão do real, afirma Marx no posfácio de 1873 para a obra $O$ Capital: "Sem dúvida, deve-se distinguir o modo de exposição segundo sua forma, do modo de investigação. A investigação tem de se apropriar da matéria [stoff] em seus detalhes, analisar suas diferentes formas de desenvolvimento e rastrear seu nexo interno. Somente depois de consumado tal trabalho é que se pode expor adequadamente seu movimento real." (MARX, 2013, p. 91). É, portanto, um método que, assim como na visão de Dussel, parte do concreto, das condições materiais. Diferente da tradição dialética anterior que privilegiava o pensamento em detrimento do mundo concreto, o método de Marx parte, segundo Chagas, de "[...] pressupostos reais e inelimináveis, da produção material da vida, dos meios para satisfazer as necessidades vitais [...]" (2011, p. 62). E Marx, avança ainda mais, trazendo ao método um momento prático: "O problema de saber se o pensamento humano pode alcançar uma verdade objectiva não é um problema teórico, mas sim um problema prático. É na prática que o homem deve provar a verdade, ou seja, a realidade e o poder do seu pensamento." (MARX, 1974, p. 8). Apesar disso, o método dialético em Marx ainda não é suficiente para uma Filosofia da Libertação, pois "[...] falta à dialética marxista a categoria da alteridade" (DUSSEL, 1986, p. 156).
} 
dos sistemas de ensino, e é neste sentido que observamos como o processo de conscientização, que veremos mais adiante, manifesta-se não necessariamente dentro de escolas ou universidades, mas na práxis, na articulação dos grupos vitimados. $\mathrm{O}$ ato pedagógico não está cristalizado no formalismo das instituições de ensino, ele é um ato revolucionário, que "[...] se dá dentro do processo da práxis de libertação" (DUSSEL, 2012, p. 443).

A articulação teoria-práxis promovida por meio de um exercício pedagógico orienta-se no horizonte do processo de conscientização:

A práxis de "transformação" não é o lugar de uma "experiência" pedagógica; não se faz para aprender; não se aprende em sala de aula com "consciência teórica". E sim na própria práxis transformativa da "realidade real" e histórica onde o processo pedagógico se vai efetuando como progressiva “conscientização" (DUSSEL, 2012, p. 441)

Há, portanto, uma dilatação da experiência pedagógica para além da "consciência teórica". A práxis de transformação desenvolve-se de forma dialética sustentada pelo processo de conscientização, pois, ao mesmo tempo em que a conscientização fundamenta a práxis, só pode existir na própria práxis. Vejamos, então, como Enrique Dussel absorve para sua filosofia o processo de conscientização teorizado por Paulo Freire e como o momento da conscientização é decisivo para a formação da “comunidade de vítimas” e para a práxis de libertação.

\section{Conscientização e Libertação}

Segundo Dussel, o ponto de partida de Freire é a realidade concreta, a condição do oprimido. "Trata-se de um ponto de partida 'material', analítico, econômico e político" (DUSSEL, 2012, p. 437). É, por exemplo, a situação do sertanejo nordestino que, apesar de ter sua consciência violentamente oprimida e ser impedido de compreender estruturalmente a realidade $^{9}$, precisa explicar o mundo em que vive. Por isso, é necessária uma pedagogia “"[...] que faça da opressão e de suas causas objeto da reflexão dos oprimidos, de que resultará o seu engajamento necessário na luta por sua libertação" (FREIRE, 1987, p.32).

O que marca o ponto de partida é o estado de "medo da liberdade", fruto de uma consciência mágica ou ingênua. De acordo com Freire, em sua Pedagogia do Oprimido, o "medo da liberdade" pode conduzir as vítimas “[...] a pretender ser opressores também, quanto pode mantê-los atados ao status de oprimidos" (1987, p. 33). Será preciso, então, romper com

\footnotetext{
${ }^{9}$ Para exemplificar essa condição, tomemos como parâmetro a taxa de analfabetismo no Brasil. Segundo dados do IBGE, o Nordeste conta com uma população de 14, $8 \%$ de analfabetos, o dobro do percentual nacional. E mais, a proporção aumenta se levarmos em conta somente as áreas rurais (BOAS, 2017).
} 
duas possibilidades articuladas dentro do sistema vigente que objetivam perpetuar a lógica de dominação das massas: 1) a reprodução da opressão e 2) o fatalismo ou mistificação da realidade. Acerca da primeira, Freire afirma que há por parte das massas oprimidas “[...] uma irresistível atração pelo opressor. Pelos seus padrões de vida. Participar destes padrões constitui uma incontida aspiração. Na sua alienação querem, a todo custo, parecer com o opressor. Imitálo. Segui-lo" (1987, p. 49). Isso ocorre quando o oprimido "hospeda" a consciência do opressor e, por conseguinte, reflete a estrutura de dominação. A ideia de "ascender" ao padrão de vida das classes mais altas, disseminada pela ilusão das ideologias que pregam a igualdade de oportunidades e a acumulação da riqueza como resultado do trabalho duro, acaba enevoando qualquer projeto de libertação; o oprimido nega sua real situação e cultiva o anseio de estar no lugar do opressor. Na não percepção da realidade e suas causas, as vítimas não vislumbram coletivamente sua libertação, ao contrário: "introjetam" a sombra do opressor e garantem a sobrevivência do sistema de dominação e exploração do homem pelo homem. Já sobre o fatalismo, argumenta:

Quase sempre este fatalismo está referido ao poder do destino ou da sina ou do fado - potências irremovíveis - ou a uma distorcida visão de Deus. Dentro do mundo mágico ou místico em que se encontra a consciência oprimida, sobretudo camponesa, quase imersa na natureza, encontra no sofrimento, produto da exploração em que está, a vontade de Deus [...] (FREIRE, 1987, p. 49).

É a religião como ópio do povo ${ }^{10}$. Sem perspectivas de conquistar uma vida materialmente suficiente, o trabalhador explorado se entrega ao fatalismo do "destino" e acredita que toda a violência que recai sobre sua existência já foi determinada por uma vontade divina e que nada poderá demovê-la, restando apenas a esperança de uma recompensa no pósmorte. Desta forma, anestesia-se, como os efeitos do ópio, a consciência das massas para qualquer movimento libertador. O trabalhador, o pobre, conforma-se na sua condição de exploração e não ameaça a lógica de dominação. Para Dussel, o temor em encarar a própria libertação revela-se como um "bloqueio" pulsional, que não é natural, mas fruto de um sistema injusto que nega a possibilidade das vítimas serem "sujeitos", restando ou o sentimento de conformismo e imutabilidade das condições materiais de vida ou o desejo de não abolir

\footnotetext{
${ }^{10}$ A ação analgésica do ópio foi lembrada por Marx para simbolizar o efeito entorpecedor que a religião pode causar quando orientada a justificar o sofrimento humano na vontade divina. Sobre o uso do termo, comenta Chagas: "A religião é também, como expresso, ilusão, compensação ideal, funcionando como um remédio, um meio de evasão, de refúgio, o ópio espiritual (geiste Opium) do povo oprimido, sofrido, como uma espécie de má 'aguardente espiritual', a qual serve para ocultar e justificar uma determinada realidade (a realidade capitalista), como uma espécie de nevoeiro, de véu sobre a irracionalidade da realidade (da produção burguesa), entontecendo, adormecendo, apaziguando a consciência do homem, amparando-o, aliviando-o, consolando-o de sua miséria no mundo real, para que ele suporte e esqueça a dureza de sua realidade degradante, levando-o, pois, ao 'gozo celeste', ao conformismo e à resignação [...]” (2017, p. 145).
} 
coletivamente o sistema de opressão, mas a ingenuidade de, individualmente, ocupar as fileiras das elites.

O ponto de rompimento da consciência ingênua está no descobrimento, por parte da vítima, de sua condição de vítima. Neste momento entra em cena o educador ou, como prefere Dussel, tomando emprestado o termo de Gramsci, o intelectual orgânico: aquele que possibilita à vítima o descobrimento de sua condição. Aqui se faz necessário salientar que é a vítima que adquire consciência crítica. O papel do educador reside unicamente no auxílio ou "despertar" da consciência, mas nunca em libertar outrem. Mas antes de educar, o educador deve educar-se a si próprio, libertar-se do tradicional método pedagógico onde ele e somente ele tem voz, e o educando recebe passivamente o conteúdo. A bagagem que o educando carrega não deve ser desprezada, é preciso levar em conta seus saberes e experiências. Para poder intervir, o educador deve instruir-se do "mundo" do educando.

Através do contato entre educadores críticos e educandos faz-se o salto da consciência ingênua para a "consciência ético-crítica". É o educador que possibilita ao educando a descoberta de sua situação:

[...] a "consciência" não chega à vítima "de fora", mas surge "de dentro" da sua própria consciência despertada pelo educador. A importância do educador consiste no fato de dar ao educando maior criticidade, ao ensiná-lo a interpretar a realidade objetiva criticamente (DUSSEL, 2012, p. 439).

Esta criticidade tem sua gênese na leitura do mundo do educando por meio de uma teoria, também crítica, que forneça uma elucidação dos porquês de toda violência e negação da vida. “[...] A análise teórica das causas da opressão do oprimido é o meio pelo qual este toma consciência da realidade objetiva que produz a sua opressão, permitindo-lhe uma apreensão explicativa mínima do argumento de caráter reflexivo, teórico, crítico” (DUSSEL, 2012, p. 439). Há, portanto, um papel a ser desempenhado pelas ciências ou, de forma mais específica, por ciências sociais críticas, que possam desmistificar a opressão e oferecer ao educando (ou à vítima do sistema) a criticidade necessária para compreender o mundo em que vive e aquilo que lhe nega o direito a desenvolver sua vida com dignidade.

Dussel assinala o distanciamento de Freire de um irracionalismo pós-moderno: a razão crítica emerge como instrumento explicativo, armada de conteúdos econômicos e políticos que subsidiam a longa caminhada da conscientização, diagnosticando o processo de domesticação e massificação sofrido pelas vítimas que, por sua vez, é resultado de uma "cultura de dominação" e de uma "educação bancária". Sem criticidade, sem consciência ético-crítica não existe educação autêntica. Ao contrário do que pensa a psicopedagogia do desenvolvimento, a função da educação não está direcionada somente ao desempenho teórico da criança. A 
autêntica educação implica na construção e reconstrução do mundo, na inserção crítica na história. Compreendendo que a estrutura social é obra humana e que ela não é imutável, cabe também aos homens a sua transformação. A educação impele à transformação social (DUSSEL, 2012, p. 440).

Com este sentido ético, de uma educação com propósito transformador, emerge um tipo de proposta pedagógica que não está voltada aos interesses do sistema dominante, tampouco reduzida a treinar o educando para uma performance teórica. É uma educação que se forma coletivamente, no diálogo entre educadores e educandos, e em diálogo com a realidade em que vivem. É, pois, uma educação que possui um conteúdo. Não um conteúdo qualquer, mas um conteúdo ético-crítico que se constrói mediante a conscientização. Para Dussel, tal característica marca também uma oposição teórica entre Freire e a Ética do Discurso.

Nas palavras de Habermas:

A ética do Discurso não dá nenhuma orientação conteudística, mas sim, um procedimento rico de pressupostos, que deve garantir a imparcialidade da formação do juízo. O Discurso prático é um processo, não para a produção de normas justificadas, mas para o exame da validade de normas consideradas hipoteticamente (1989, p.148).

Além da questão referente ao conteúdo, Dussel insiste que a comunidade de comunicação proposta pela Ética do Discurso é falha porque não leva em conta a voz da vítima. É um sistema democrático que não é democrático o suficiente, já que não garante simetricamente a participação das vítimas do sistema no sistema (DUSSEL, 2012, p. 217). Somente com a Ética da Libertação o dilema da simetria é dirimido, e pode-se falar finalmente em discurso válido e consensual crítico:

\begin{abstract}
Alcança-se validade crítica quando, tendo construído uma comunidade de vítimas, que se re-conhecem como dis-tintas do sistema opressor, participam simetricamente nos acordos sobre o que lhes toca, sustentando além disso que esse consenso crítico se fundamenta por argumentação racional e é motivado por cossolidariedade pulsional. Esse consenso crítico se desenvolve, como veremos adiante em c, (a) negativamente, chegando a compreender e explicar as causas de sua alienação, e (b), positivamente, antecipando criativamente alternativas futuras (utopias) e projetos possíveis (DUSSEL, 2012, p. 468).
\end{abstract}

Os elementos que garantem a factibilidade de uma comunidade de vítimas estão presentes no pensamento freiriano. É lá que Dussel vai buscar a base teórica que o permite ir além da Ética do Discurso. É no processo de conscientização e numa teoria do diálogo que reside a grande contribuição de Paulo Freire. Para ele, os oprimidos, conscientes de sua condição, mediados pelo educador, encontram no diálogo o instrumento de mobilização para a práxis. Por isso o caráter coletivo da práxis. A práxis de libertação não se constrói no solipsismo 
teórico, mas na ação crítica coletiva validada por uma prática intersubjetiva, a ação dialógica: “se é dizendo a palavra com que, 'pronunciando' o mundo, os homens o transformam, o diálogo se impõe como caminho pelo qual os homens ganham significação enquanto homens" (FREIRE, 1987, p. 79). E mais, a existência humana, a problematização e a transformação do mundo são mediadas dialeticamente pelo diálogo, num exercício comunitário de leitura e compreensão do mundo:

A existência, porque humana, não pode ser muda, silenciosa, nem tampouco pode nutrir-se de falsas palavras, mas de palavras verdadeiras, com que os homens transformam o mundo. Existir, humanamente, é pronunciar o mundo, é modificá-lo. O mundo pronunciado, por sua vez, se volta problematizado aos sujeitos pronunciantes, a exigir deles novo pronunciamento (FREIRE, 1987, p. 80).

No pensamento de Habermas "[...] a ação comunicativa surge como uma interação de, no mínimo dois sujeitos, capazes de falar e agir, que estabelecem relações interpessoais com o objetivo de alcançar uma compreensão sobre a situação em que ocorre a interação e sobre os respectivos planos de ação com vistas a coordenar suas ações pela via do entendimento" (PINTO, 1995, p. 85). O sucesso dessa ação comunicativa esbarra num obstáculo empírico que os teóricos da Ética de Discurso não superaram: como garantir a participação das vítimas, dos excluídos, num acordo consensual? Segundo Dussel:

\begin{abstract}
A Ética da Libertação supera essa aporia ao descobrir que as vítimas excluídas assimetricamente da comunidade de comunicação hegemônica se reúnem em uma comunidade crítico-simétrica. Aparentemente se trataria de um mero desenvolvimento ou dedução da Ética do Discurso, mas não é assim. A Ética da Libertação pode contar com a luta pelo re-conhecimento das próprias vítimas excluídas, que se tornaram sujeitos re-sponsáveis por sua própria libertação, porque pode aproveitar-se dos momentos material, de factibilidade e crítico. No simples nível formal acrítico, da consensualidade de validade intersubjetiva, a moral procedimental não é capaz de superar o "círculo" da única comunidade de comunicação (quer ideal ou empírica), que lhe impede realizar empiricamente mediante a argumentação uma simetria inexistente - não havendo simetria a argumentação prática moral não é possível. A Ética da Libertação, muito mais complexa, pode contar com comunidades de comunicação ideais e empíricas, hegemônicas e de vítimas. Acredito que se tenha aberto assim um novo horizonte problemático da razão discursiva-crítica, comunitária anti-hegemônica, da maior importância para os novos movimentos sociais da sociedade civil, dos partidos políticos críticos, dos sujeitos sociais "emergentes" na sociedade civil. Apel ou Habermas, pelo o que vi, não vislumbraram estas possibilidades discursivas crítico-comunitárias do seu próprio discurso (2012, p. 465).
\end{abstract}

O processo de conscientização e seus desdobramentos na articulação dos oprimidos por meio de uma ação dialógica superam a chamada comunidade de comunicação dos filósofos europeus e suas limitações. Paulo Freire antecipadamente já pensara uma teoria intersubjetiva, dialógica, que garantia voz e reconhecimento à palavra do oprimido e, mais ainda, que fomentava a transformação social mediante a análise coletiva e crítica da realidade. Assim caminha o processo de conscientização: da percepção da condição de vítima, passando pelo 
entendimento das causas da opressão, chegando à luta por reconhecimento e libertação. Tudo isso realizado coletivamente, não somente por meio de um exercício teórico, nem restrito a um mero ativismo, mas unindo teoria e prática ${ }^{11}$. A teoria de Freire dá um salto em relação à Ética do Discurso por determinar como norte um conteúdo ético-crítico e por não só incluir, mas ter como objeto central a ação da vítima, que toma consciência crítica e insere-se na história, na reconstrução da estrutura social.

Após o que foi exposto, é possível afirmar que o resgate feito por Dussel das ideias pedagógicas de Freire é essencial para o desenvolvimento do seu projeto-libertação, para a formação da comunidade de vítimas e superação da comunidade intersubjetiva proposta pela Ética do discurso habermasiano. Assim, poderíamos dizer que a práxis de libertação principia no momento descrito por Freire como conscientização e segue por meio de uma ação intersubjetiva, simétrica, dialógica. Por isso, o trabalho de Freire não é apenas complementar, mas fundamental à Ética da Libertação.

\section{Conclusão}

Neste breve artigo, expomos o grande impacto que as ideias do patrono da educação brasileira exerceram na Ética da Libertação de Enrique Dussel. Destacamos duas fundamentais categorias da obra de Freire, a conscientização e a dialogicidade, que foram subsumidas por Dussel em sua admirável arquitetura teórica. As ideias de Freire abriram espaço para que a Filosofia da Libertação avançasse na relação teoria-prática em vista do seu projeto-libertação. Graças a esta contribuição teórica foi possível tematizar a construção de uma comunidade de vítimas, a esfera de gestação das Frentes de Libertação. É inegável, portanto, não apenas a imprescindibilidade de Paulo Feire, mas também o caráter essencial da dimensão pedagógica para o desenvolvimento deste pensamento ético.

\footnotetext{
${ }^{11}$ A atuação da comunidade de vítimas é fruto do processo de conscientização, que une reflexão e práxis: "Somente quando os oprimidos descobrem, nitidamente, o opressor, e se engajam na luta organizada por sua libertação, começam a crer em si mesmos, superando, assim, sua 'convivência' com o regime opressor. Se esta descoberta não pode ser feita em nível puramente intelectual, mas da ação, o que nos parece fundamental é que esta não se cinja a mero ativismo, mas esteja associada a sério empenho de reflexão, para que seja práxis" (FREIRE, 1987, p. 52).
} 


\section{REFERÊNCIAS BIBLIOGRÁFICAS}

BOAS, Bruno Villas. IBGE: Brasil tem 11,8 milhões de analfabetos; metade está no Nordeste. Valor econômico. São Paulo, 21 dez. 2017. Disponível em: $<$ https://www.valor.com.br/brasil/5234641/ibge-brasil-tem-118-milhoes-de-analfabetosmetade-esta-no-nordeste > .Acesso em: 29 ago. 2019.

CHAGAS, Eduardo Ferreira. A crítica da religião como crítica da realidade social no pensamento de Karl Marx. In: Trans/Form/Ação. Marília, v. 40, n. 4, Out./Dez., 2017, p. 133154.

. O método dialético de Marx: investigação e exposição crítica do objeto. In: Síntese. Belo Horizonte, v. 38, n. 120, 2011, p. 55-70.

DUSSEL, Enrique. Ética da libertação: na idade da globalização e da exclusão. Tradução de Ephraim Ferreira Alves, Jaime A. Clasen, Lúcia M. E. Orth. 4 ed. Petrópolis, Vozes: 2012.

. Filosofia da Libertação: na América latina. Tradução de Luiz João Gaio. São Paulo, Edições Loyola: 1977.

. Método para uma filosofia da libertação. Tradução de Jandir João Zanotelli. São Paulo, Loyola: 1986.

Para uma Ética da Libertação Latino-Americana: erótica e pedagógica. Tradução de Luiz João Gaio. Tomo III. São Paulo, Edições Loyola-UNIMEP: 1982.

FREIRE, Paulo. Pedagogia do Oprimido. 17 ed. Rio de Janeiro: Paz e Terra, 1987.

HABERMAS, Jurgen. Consciência moral e agir comunicativo. Tradução de Guido A. de Almeida. Rio de Janeiro: Tempo Brasileiro, 1989.

MARX, Karl. O Capital: Crítica da economia política. Livro I. Trad. Rubens Enderle. São Paulo: Boitempo, 2013.

Teses sobre Feuerbach. In: MARX, Karl; ENGELS, Friedrich. Textos Filosóficos. Porto: Editorial Presença, 1974.

OLIVEIRA, Manfredo Araújo de. Ética, direito e democracia. São Paulo: Paulus, 2010.

PINTO, José Marcelino. A teoria da ação comunicativa de Jürgen Habermas: conceitos básicos e possibilidades de aplicação à administração escolar. Paideia. Ribeirão Preto: USP, fev/ago, 1995. p. 77-96. 